\title{
Stress redistribution in flat damaged trusses
}

\author{
Maria Berger* and Alexander Tusnin \\ Moscow State University of Civil Engineering, Yaroslavskoe shosse, 26, Moscow, 129337, Russia
}

\begin{abstract}
An important problem of modern engineering is to ensure the stability of buildings to a progressive collapse. One of the options for making calculations is to perform a static calculation with the use of the dynamic coefficient. The dynamic factors of damage of the structure depend on the failure time of the element, i.e. time during which the resistance of the damaged element is reduced to zero.To determine the time of exclusion, a series of experimental studies of stretched and compressed steel samples was carried out. The work of elements was studied after they had exhausted their carrying capacity (strength or stability). The results of a numerical study of a truss with damaged elements are presented. It is established that a significant part of the load is redistributed to the intact elements of the truss during deformations of the excluded element are smaller than the experimentally established deformations of the rods.
\end{abstract}

\section{Introduction}

When designing important buildings and structures, special attention should be paid to the robustness of bearing structures, their ability to maintain strength and stability even when damaged individual elements. The calculation of the stability of buildings and structures to progressive collapse in Russia is carried out in accordance with current regulations [1, 2]. The load on structures is determined in accordance with regulatory requirements [3]. In many countries, there are relevant regulatory guidelines for calculating survivability [4-9].

The destruction of individual structural elements is often accompanied by the development of oscillations in the structure. The forces and displacements of the structure in this case will be greater than with static loading of the damaged structure. One of the options for making calculations on the stability of buildings to a progressive collapse is to perform a static calculation with the use of the dynamic coefficient [10-12]. This approach allows the design to perform calculations in a linear formulation using different engineering analysis programs $[13,14]$. In these complexes, standard procedures for testing the strength and stability, algorithms for determining the calculated combinations of forces are well developed. For the correct application of static calculation, it is important to reasonably assign the dynamic coefficient. The value of the dynamic coefficient depends on the actual load, the type of structure, the location of the damaged element in it and the failure time of the element or the time of elimination. To determine the dynamic coefficients, the method of numerical calculation of the structure turned out to be very productive, in which the damaged element is replaced by the forces acting in it in an intact state. Forces are made

\footnotetext{
* Corresponding author: marieberger@yandex.ru
} 
with a sign opposite to the forces in the element, and then reduce to zero for a specified period of time - the time of elimination.

The elimination time depends on the cause of the element damage and the type of stressed state. So, in case of fire, even in the worst case, the time of heating the steel element to a critical temperature, by which the strength of the steel is exhausted is at least 15 minutes. With settlement of foundation, the failure time of an element is several days or more. The considerable failure time allows calculating the damaged structure as statically loaded. The construction works in a completely different way with exhaustion of strength or with loss of stability of the element. Such damage occurs in a short period of time, therefore, in the process of elimination of an element, the structure works dynamically. Analysis of the process of failure of the element, the study of the dependence of the time of exclusion on the type of stress-strain state of the rod is an important task, the successful solution of which will allow to assign the value of the dynamic coefficient.

It is necessary to study how in the process of elimination of a damaged element the redistribution of forces in the structure occurs. It should be considered change of forces in the structure with a consistent deformations increase of the eliminated element. Comparison of the level of stresses during deformations, corresponding to those obtained during testing of the rods, will allow reasonably assign the time for elimination of the element for calculating the dynamic coefficient.

\section{Methods}

The failure time of the element $\Delta t$ in case of damage is justified experimentally when conducting a series of tests of centrally stretched and centrally compressed rods. The research was aimed at obtaining data on the operation of the rods after the beginning of destruction (for stretched rods) or loss of stability (for compressed rods).

For the experiment were chosen steel square solid rods according to GOST 2591-2006 [15]. Three samples were tested for stretching, and four samples for compression (Figure 1).

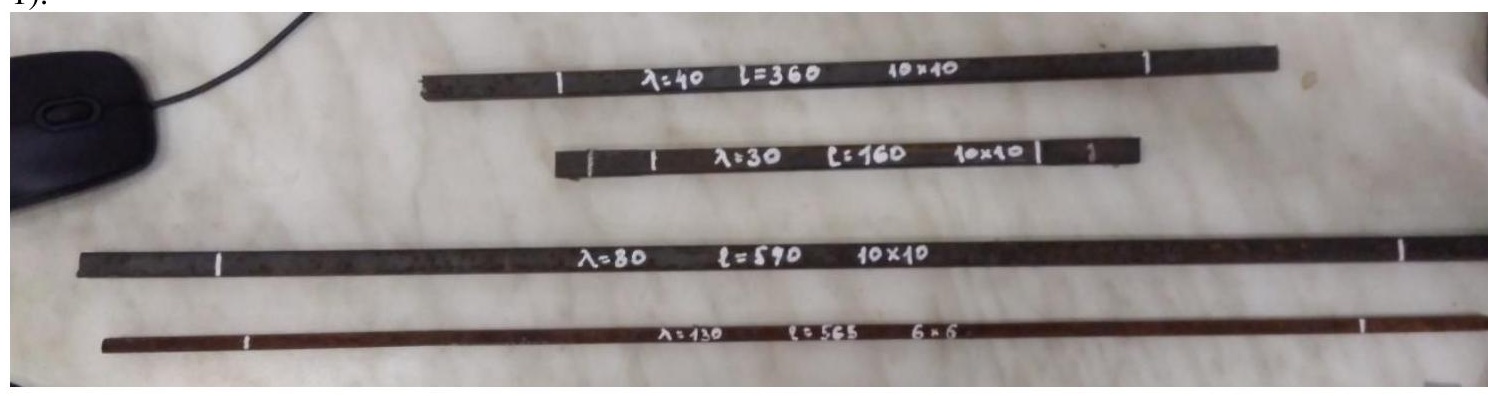

Fig. 1a. Compression test specimens.

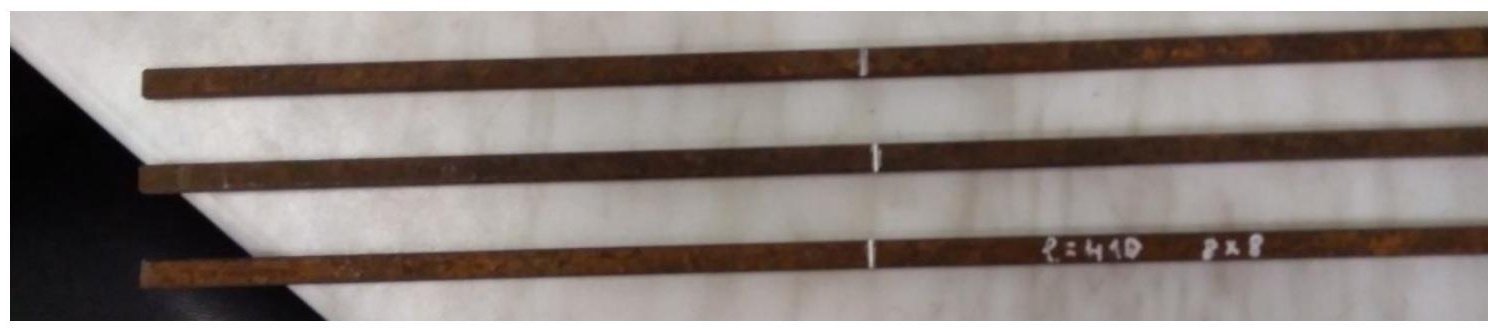

Fig. 1b. Tensile test specimens

Samples for stretch test had a cross-section $8 \times 8 \mathrm{~mm}$. The rod was attenuated by a "V"shaped notch on two opposite sides (Figure 2). Concentrators were arranged with a device 
used in the testing of steel for impact strength. This allowed to simulate the most unfavorable process of destruction without the development of plastic deformations.
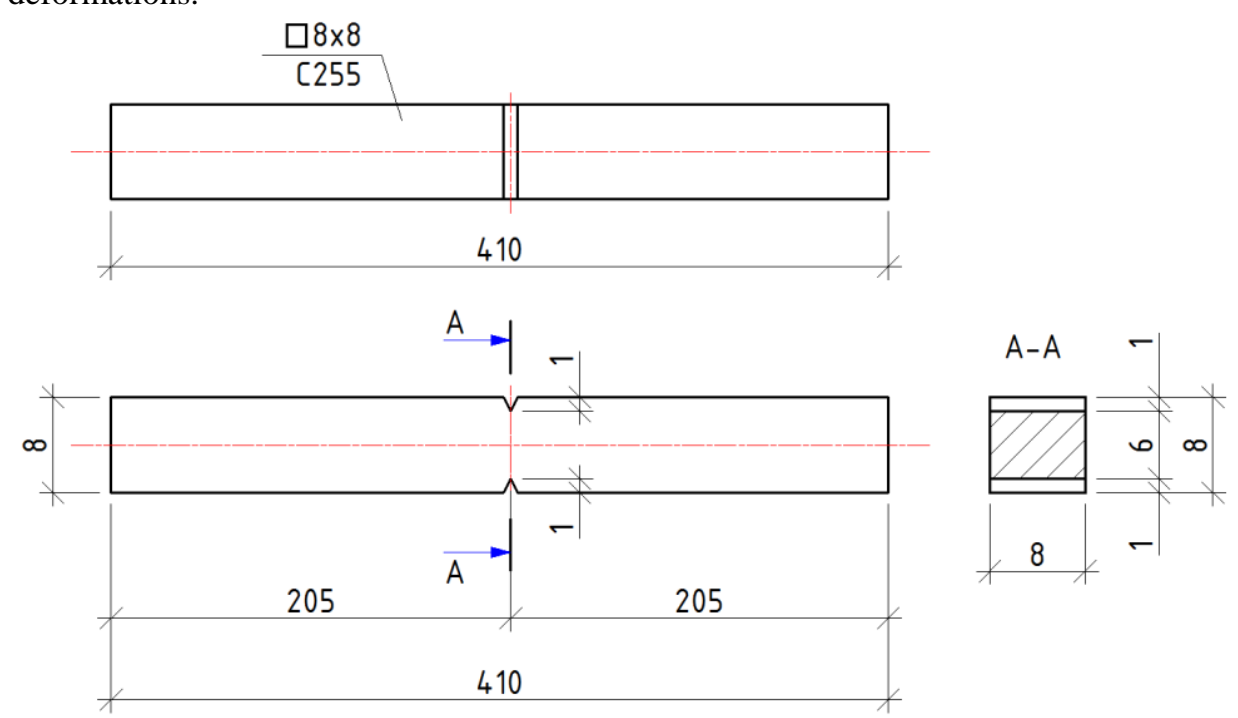

Fig. 2. The scheme of the location of the V-shaped notch

For compression, four samples with different cross sections and flexibility were tested. The parameters of centrally compressed samples are presented in Table 1.

Table 1. The parameters of centrally compressed samples

\begin{tabular}{|l|c|c|c|c|}
\hline & 1 sample & 2 sample & 3 sample & 4 sample \\
\hline Length, mm & 160 & 250 & 480 & 455 \\
\hline Cross-section, $\mathrm{mm}$ & $10 \times 10$ & $10 \times 10$ & $10 \times 10$ & $6 \times 6$ \\
\hline Flexibility, $\lambda$ & 30 & 40 & 80 & 130 \\
\hline
\end{tabular}

The tensile test specimens are made of unalloyed structural steel of ordinary quality type VSt5sp. Steel VSt5sp refers to medium-carbon steels (carbon content $0.28-0.37 \%$ ) with a relative yield line, ultimate tensile strength $\sigma \mathrm{B}=620 \mathrm{MPa}$, yield point $\sigma 0.2=$ 570MPa. According to international standards ISO 630:1995 and ISO 1052:1982, this steel corresponds to the types E-355-C (Fe 510-C) and Fe 490 [16, 20]. In figure 3 red line shows the load-extension diagram, obtained from the results of verification tests for determination steel type. Green line is a graph of stress versus deformation for one of the tensile samples with a weakened section. It can be seen that it practically does not have a horizontal segment correspond to plastic response of the steel. Thus, during the tests it was possible to simulate an almost brittle fracture. 


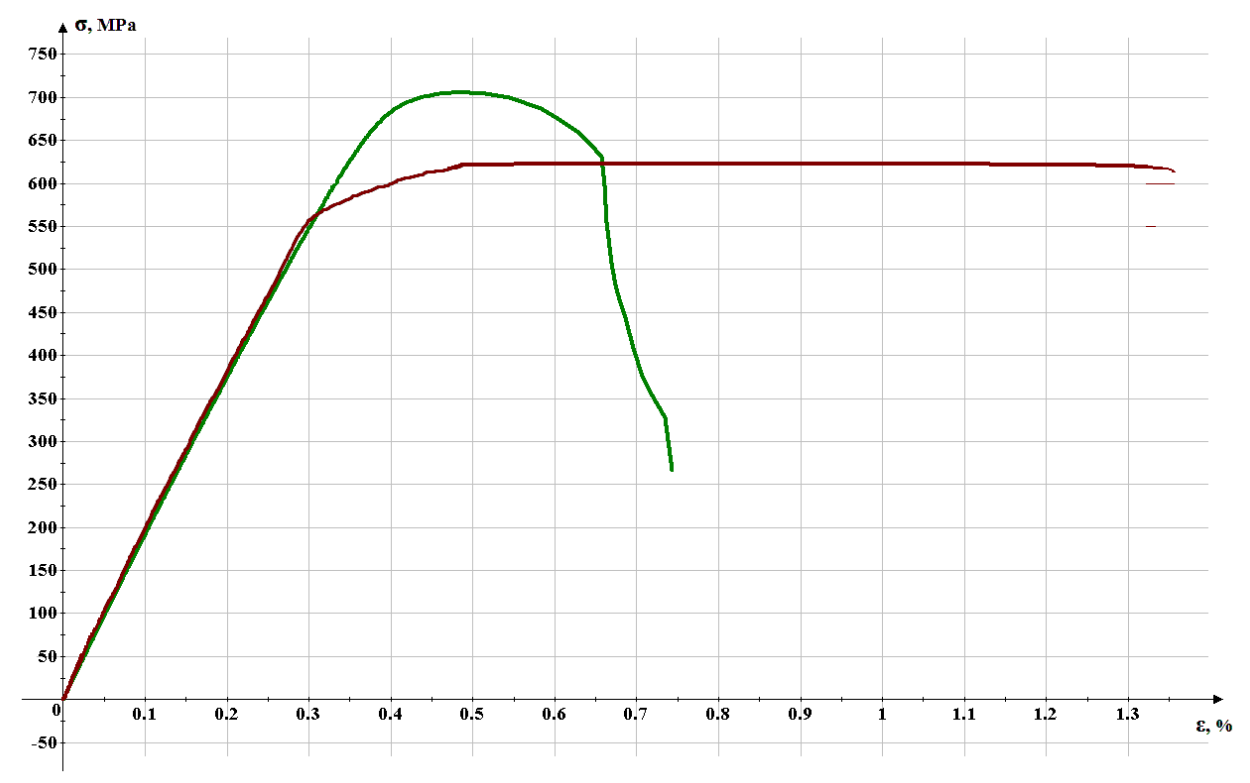

Fig. 3. Deformation, $\%$ vs. stress, MPa graph (tensile sample)

An experiment conducted in 2017 consisted in stretching and compressing samples on a servo-hydraulic machine for static and dynamic testing (Instron8802). The experiment was carried out and funded by the Center of shared usage of equipment NRU MSUCE. After the exhaustion of the bearing capacity, the testing machine applied the load so that the resistance of the rod with the growth of its deformations corresponded to the applied load. During the tests, the load, deformations of the rod end and time were recorded. The obtained data were generated in the MS Excel table and then processed using the Advanced Grapher, ver. 2.2.

Numerical studies of the redistribution of efforts in farms with the exclusion of elements were performed as follows. In the calculations, the damaged element was selected and the modulus of elasticity decreased step by step in it, which led to a decrease in the stiffness of the rod and allowed modeling the elimination of the element. With a decrease in the stiffness of the rod, its deformation increased. The deformations of the excluded rod were calculated as the ratio of the elongation or shortening of the rod to the original length of the element. Calculations are made for trusses with a span of $24 \mathrm{~m}$. The figure 4,5 shows the scheme farms with damaged elements.

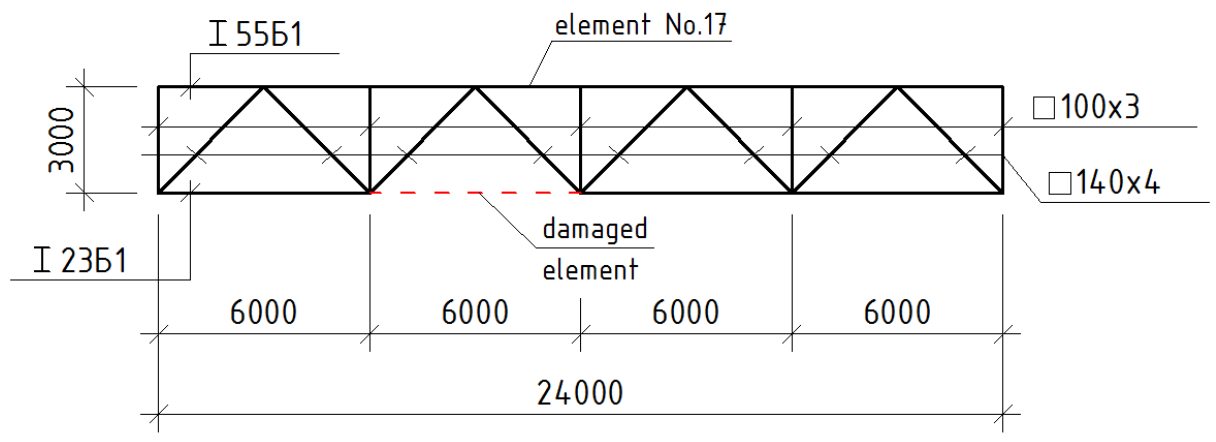

Fig. 4. The geometrical scheme of the farm with a damaged lower belt 


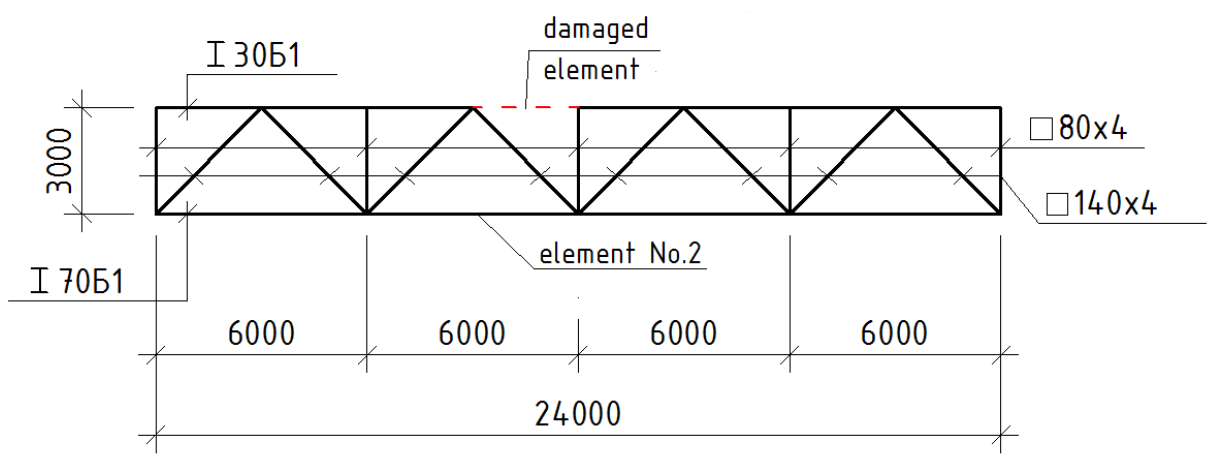

Fig. 5. The geometrical scheme of the farm with a damaged upper belt

The calculation of farms was performed in a linear formulation. Reducing the stiffness of the excluded rod leads to an increase of forces in the remaining rods of the truss. The value of the bar stress reaches maximum at a certain value of the stiffness of the rod being removed, and with a further decrease in the stiffness, the efforts change little. The strains corresponding to this stiffness were compared with the strains of the experimental samples. On the basis of this comparison, a conclusion was made about the failure time of the element, which should be used in case of damage to the element to determine the dynamic coefficient.

\section{Results}

The figure 6 shows the load-strain relationships for the stretched specimens, in the figure 7 are shown the same dependences for the compressed specimens. The yellow marker on the graphs indicates the bearing capacity of the rods.

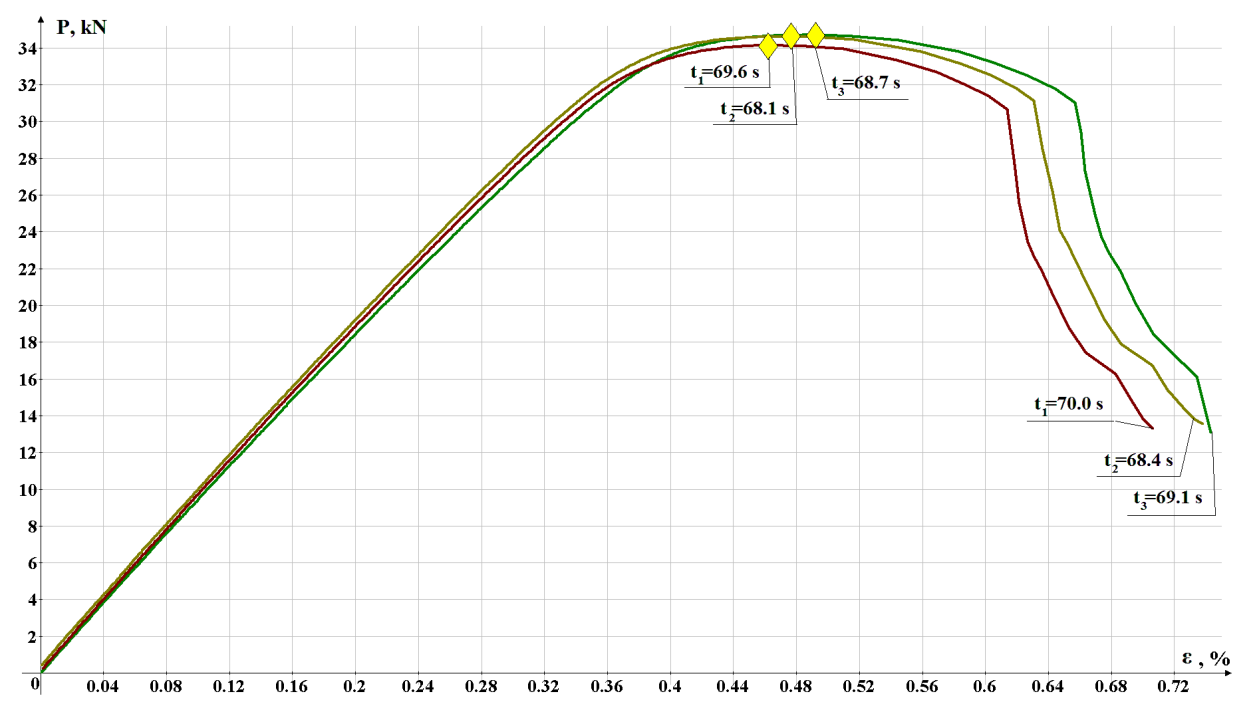

Fig. 6. Load vs. deformation graph for stretched samples

Green line - sample number 1; red line - sample number 2; yellow line - sample number 3 


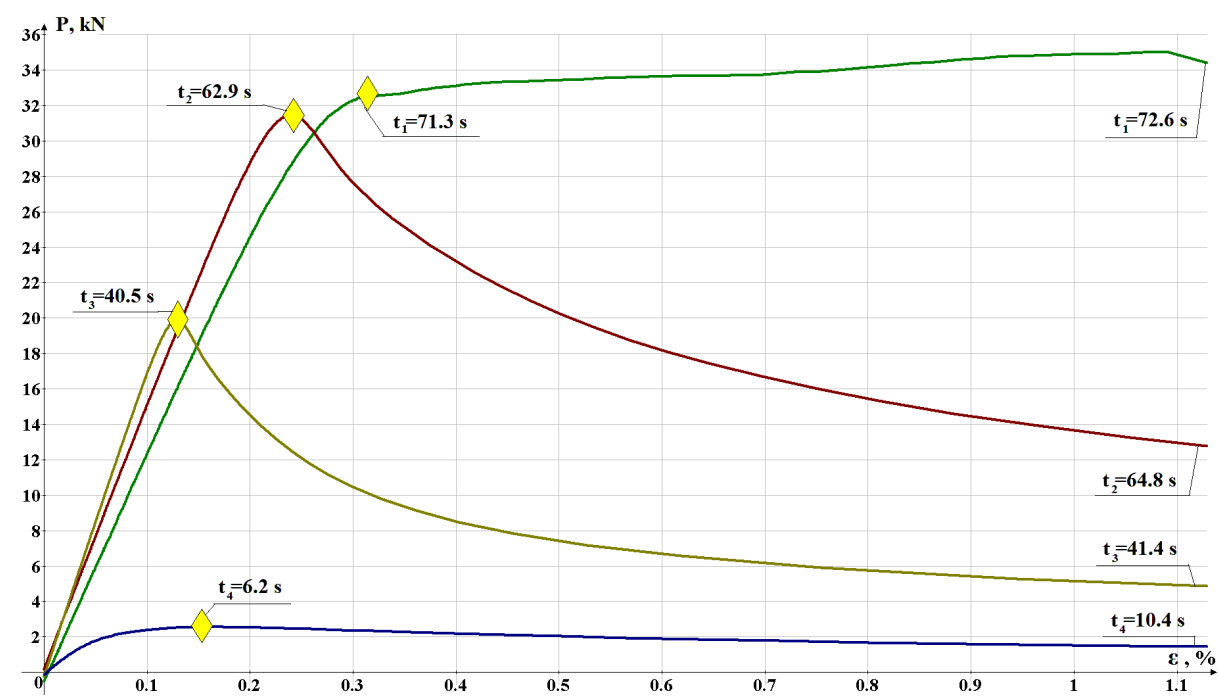

Fig. 7. Load vs. deformation graph for compressed samples

Green line - sample number $1, \lambda=30$; red line - sample number $2, \lambda=40$; yellow line - sample number $3, \lambda=80$; blue line - sample number $4, \lambda=130$.

After reaching the maximum load, both the stretched and compressed specimens retained a certain bearing and provided resistance. The deformations (relative removal or convergence of the clamps of the machine) after reaching the ultimate load before the tests were terminated were: for stretched rods from $0.45 \%$ to $0.74 \%$, for compressed rods from $0.13 \%$ to $30.6 \%$. The time of deformation after exhaustion of the bearing was as follows: for tensioned rods from $0.34 \mathrm{~s}$ to $0.43 \mathrm{~s}$, for compressed rods from $0.9 \mathrm{~s}$ to $4.0 \mathrm{~s}$. Figures 8 , 9 show graphs of time versus load for stretched (Fig. 8) and compressed (Fig. 9) rods. Vertical blue lines indicate deformations corresponding to the beginning of element failure (in Fig. 6, 7 marked with yellow markers).

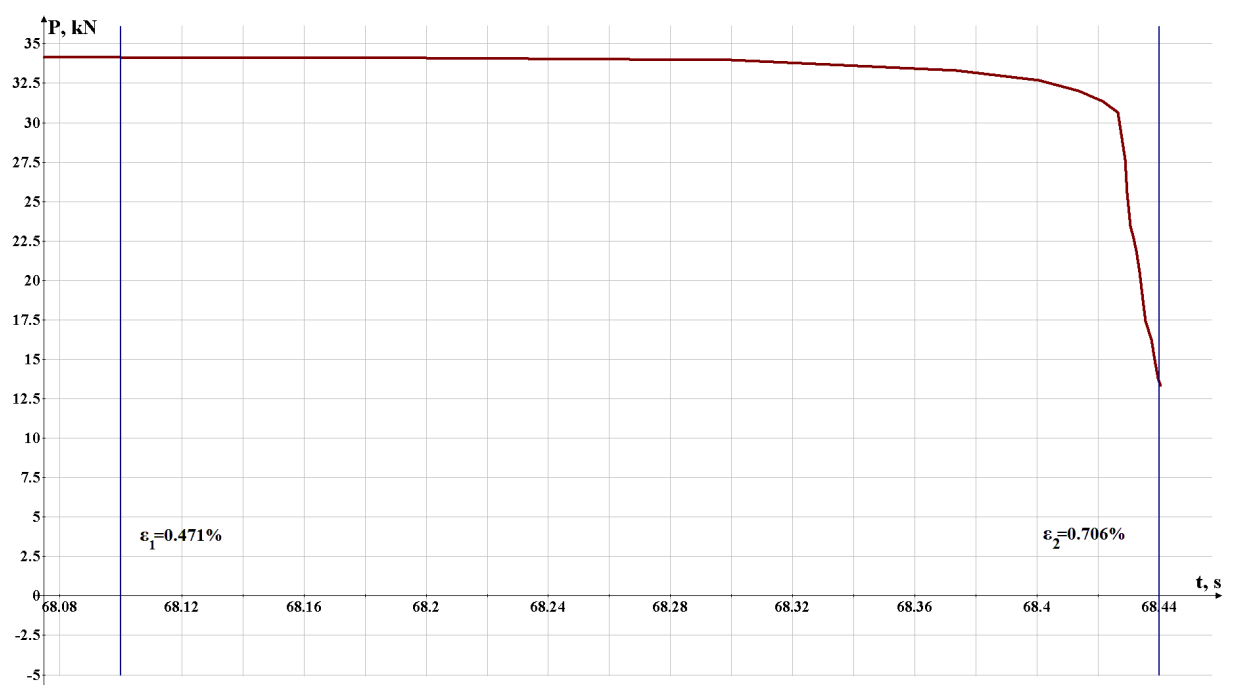

Fig. 8. Load vs. deformation graph for stretch sample after loss of the bearing 


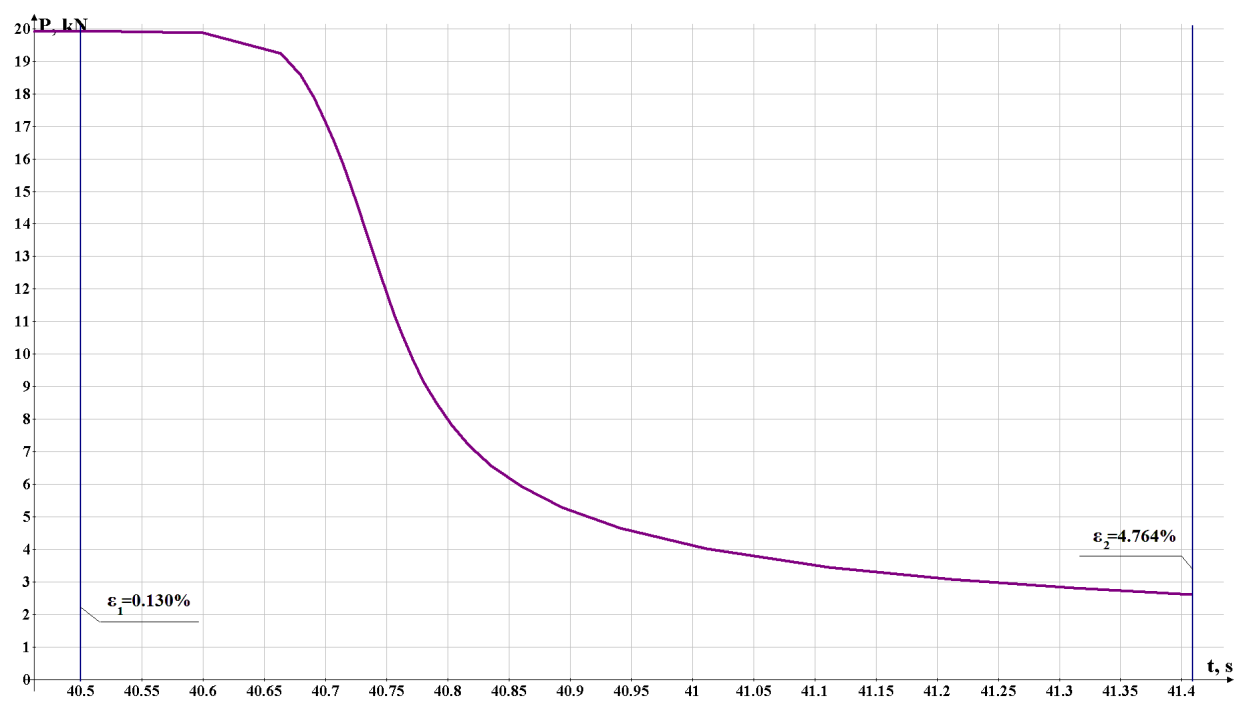

Fig. 9. Load vs. deformation graph for compressed sample $(\lambda=80)$ after loss of stability

The destruction of the tested stretched rods occurs with an insignificant development of plastic deformations, which amounted to no more than $15 \%$ of the deformations corresponding to the yield strength, which is 2-3 times less than the deformations of destruction of a plain specimen. Thus, the destruction of stretched rods was almost brittle, which allows the use of experimental data to assess the process of destruction of stretched elements in the most unfavorable variant of damage. An analysis of the experimental data showed that for stretched elements with constrained development of plastic deformations, the average failure time after exhaustion of the bearing was $0.37 \mathrm{sec}$. Repeller rod with an increase in deformation of about $0.16 \%$ after reaching the maximum strength of the rod is reduced by $10 \%$. With further growth of deformation repulse decreases by more than 2 times.

For compressed rods, the operating time of the rod after loss of stability varies from 1 to 4 seconds and depends on the flexibility of the rod. With the growth of deformations up to $1 \%$, the reduction in repulse for a rod with a flexibility of 130 is $26 \%$, with a flexibility of 80 - by a factor of 3.5 , with a flexibility of 40 - by a factor of 2.3 . With flexibility of 30 , an increase in strain to $1 \%$ is accompanied by an increase in resistance by $8 \%$.

Numerical calculations of the trusses showed that with a decrease in the stiffness of the excluded element, the forces in the other elements of the truss increase. Tables 2 and 3 show the deformations in the excluded rod and the forces in the truss elements with a span of $24 \mathrm{~m}$ with a decrease of the stiffness of the excluded element.

Table 2. Deformations and stresses at damage of a lower belt

\begin{tabular}{|c|c|c|c|c|c|}
\hline $\begin{array}{c}\text { Coefficient } \\
\text { of elasticity } \\
\mathbf{E}, \mathrm{t} / \mathrm{m}^{2}\end{array}$ & $\begin{array}{c}\text { Deformation, \% } \\
\text { (damaged } \\
\text { element })\end{array}$ & $\begin{array}{c}\text { Lateral force } \\
N, k N \\
\text { (damaged } \\
\text { element) }\end{array}$ & $\begin{array}{c}\text { Lateral force } \\
N, k N \\
(\text { element } \\
\text { No.17) }\end{array}$ & $\begin{array}{c}\text { Design } \\
\text { moment } M, \\
t \cdot m(\text { element } \\
\text { No.17) }\end{array}$ & $\begin{array}{c}\text { Stress, } M P a \\
\text { (element No.17) }\end{array}$ \\
\hline $2.1 \cdot 10^{7}$ & 0.0033 & 179.4 & 189.0 & 3.15 & 20.81 \\
\hline $2.1 \cdot 10^{6}$ & 0.0323 & 171.2 & 189.3 & 3.17 & 26.97 \\
\hline $2.1 \cdot 10^{5}$ & 0.2190 & 116.3 & 189.4 & 17.28 & 66.66 \\
\hline
\end{tabular}




\begin{tabular}{|l|c|c|c|c|c|}
\hline $\mathbf{2 . 1} \cdot 1 \mathbf{1 0}^{\mathbf{4}}$ & $\mathbf{0 . 5 2 0 8}$ & $\mathbf{2 7 . 7}$ & $\mathbf{1 8 9 . 6}$ & $\mathbf{4 3 . 4 7}$ & $\mathbf{1 3 0 . 7 6}$ \\
\hline $2.1 \cdot 10^{3}$ & 0.6040 & 3.2 & 189.6 & 50.7 & 148.44 \\
\hline $2.1 \cdot 10^{2}$ & 0.6139 & 0.3 & 189.6 & 51.55 & 150.52 \\
\hline $2.1 \cdot 10$ & 0.6149 & 0.03 & 189.6 & 51.64 & 150.73 \\
\hline
\end{tabular}

Table 3. Deformations and stresses at damage of an upper belt

\begin{tabular}{|c|c|c|c|c|c|}
\hline $\begin{array}{c}\text { Coefficient } \\
\text { of elasticity } \\
\mathbf{E}, \mathrm{t} / \mathrm{m}^{2}\end{array}$ & $\begin{array}{c}\text { Deformation, \% } \\
\text { (damaged } \\
\text { element) }\end{array}$ & $\begin{array}{c}\text { Lateral force } \\
N, k N \\
\text { (damaged } \\
\text { element) }\end{array}$ & $\begin{array}{c}\text { Lateral force } \\
\mathrm{N}, \mathrm{kN} \\
(\text { element } \\
\text { No.2) }\end{array}$ & $\begin{array}{c}\text { Design } \\
\text { moment } M, \\
t \cdot m(\text { element } \\
\text { No.2) }\end{array}$ & $\begin{array}{c}\text { Stress, } M P a \\
\text { (element No.2) }\end{array}$ \\
\hline $2.1 \cdot 10^{7}$ & 0.0010 & 188.5 & 168.0 & 3.31 & 17.71 \\
\hline $2.1 \cdot 10^{6}$ & 0.0073 & 187.4 & 167.4 & 3.23 & 18.14 \\
\hline $2.1 \cdot 10^{5}$ & 0.0690 & 175.5 & 161.7 & 6.45 & 22.14 \\
\hline $2.1 \cdot 10^{4}$ & 0.4131 & 105.0 & 132.0 & 27.77 & 44.46 \\
\hline $2.1 \cdot 10^{3}$ & 0.8202 & 20.9 & 97.4 & 53.0 & 70.91 \\
\hline $2.1 \cdot 10^{2}$ & 0.9101 & 2.3 & 89.7 & 58.56 & 76.73 \\
\hline $2.1 \cdot 10$ & 0.9200 & 0.2 & 88.9 & 59.18 & 77.38 \\
\hline
\end{tabular}

Analysis of the data presented in the tables showed the following. Deformations in the excluded element of the stretched lower belt, equal to the deformations of exhaustion of the bearing capacity of the tested stretched samples $(0.42-0.49 \%)$, lead to the appearance of stresses in the most loaded element of the upper belt up to $81 \%$ of the maximum stresses in it after removal of the damaged rod. Deformations in the excluded element of the compressed upper belt, equal to deformations of exhaustion of the carrying capacity of the tested compressed samples $(0.13-0.32 \%)$, lead to the appearance of stresses in the most loaded element of the upper belt from 33 to $50 \%$ of the maximum stresses in it after removal of the damaged rod. For compressed rods, the experimentally established presence of a significant rebuff after exhaustion of the bearing capacity over a long stretch of deformation (with deformations up to $1 \%$ ) should be taken into account.

\section{Discussion}

In $[17,18]$, the failure time of an element from forces in a structure is investigated. The time is set as a fraction of the natural period of vibrations of the system $(1 / 100,1 / 10,1,4$ of the natural period of vibrations). With the failure time of the element over 4 of the natural periods of vibrations, the increase in efforts in the damaged structure is not more than $10 \%$. As a "momentary" failure of an element, the authors recommend taking a period of no more than $1 / 10$ of the natural periods of vibrations. In [19], the calculation of an emergency situation of an arched bridge, in which cable failures occur, is considered. According to the 
results presented in the article, the magnitude of the failure time of a structure over $1 \mathrm{~s}$ has little effect on the resulting forces and deformations.

The results obtained during testing of samples showed that the failure time for the excluded rod is determined by its stress-strain state and is not related to the natural period of vibrations. After the bearing has been exhausted, the rod resists external influence and thus continues to work partially as part of the structure significant periods of time (from 0.37 s. to $4 \mathrm{~s}$.). Comparison of the experimental deformations of the rod with the deformations of the damaged element in numerical calculations showed that with relatively small deformations of the excluded rod, a significant part of the forces is redistributed to the remaining elements of the truss. Thereby, excluding the corresponding share of the load from the dynamic effect on the structure when the rod is removed.

\section{Conclusions}

Experimental studies of samples of steel rods made it possible to establish that after the bearing (strength or stability) was exhausted, the rods retain the possibility of exerting some resistance to external influence. The deformations (relative removal or convergence of the machine clamps) after reaching the ultimate load before the tests were terminated were: for stretched rods from $0.45 \%$ to $0.74 \%$, for compressed rods from $0.13 \%$ to $30.6 \%$, and time, respectively, from $0.34 \mathrm{~s}$. to $0.43 \mathrm{~s}$, and from $0.9 \mathrm{~s}$. up to $4.0 \mathrm{~s}$. The presence of an extended area of the element after the exhaustion of its carrying capacity allows the design to reduce the dynamic factor for the structure.

It is numerically established that part of the load is redistributed to the undamaged elements of the truss during deformations of the excluded element smaller than the limiting deformations of the rods that were detected during the tests. When performing calculations for farms with damage, the redistributed part of the load does not participate in the formation of dynamic forces.

\section{References}

1. SP 385.1325800.2018. Protection of buildings and structures against progressive collapse. Design code. Basic statements, 21 (2018)

2. GOST 27751-2014 Reliability for constructions and foundations. General principles, 16 (2014)

3. SP 296.1325800.2017. Buildings and structures. Accidental actions , 23 (2017)

4. EN 1991-1-7 Eurocode 1: Actions on structures - Part 1-7: General actions Accidental actions (The European Union), 67 (2006)

5. UFC 4-023-03 Design of buildings to resist progressive collapse (USA: Department of Defense), 245 (2013)

6. ASCE/SEI 7-10 Minimum Design Loads for Buildings and Other Structures (American Society of Civil Engineers), 658 (2010)

7. Code of practice for the structural use of steel (The Government of the Hong Kong Special Administrative Region), 388 (2011)

8. NISTIR 7386 Best Practices for Reducing the Potential for Progressive Collapse in Buildings (U.S. Department of Commerce / Technology Administration / National Institute of Standarts and Technology), 216 (2007)

9. AS/NZS 1170.0:2002 Australian/New Zealand Standard. Structural design actions. Part 0: General principles (SAI Global Limited), 42 (2002)

10. Y.I. Kudishin, D.U. Drobot, Steel buildings, Robustness of structures in emergency situation, 4(8), 20 (2008) (In Russian) 
11. Y.I. Kudishin, Bulletin of MGSU, Conceptual problems of survivability of building structures, 2, 28 (2009) (In Russian)

12. V.Y. Grachev, T.A. Vershinina, A.A. Puzatkin, Disproportionate destruction. Comparison of calculation methods, Ekaterinburg: Azhur, 81 (2010) (In Russian)

13. I.S. Kukushkin, CADMASTER, SCAD OFFICE V.21 New look., 370 (2014) (In Russian)

14. R.Y. Vodopyanov., V.P. Titok, A.E. Artamonov, M.A. Romashkina LIRA SAPR 2017. User Guide. Learning examples (Electronic edition), 535 (2017)

15. GOST 2591-2006 Square hot-rolled steel bars. Dimensions (Moscow: Standartinform) 8 (2009)

16. A.S. Zubchenko, Marker steel and alloys, (Moscow Mechanical Engineering), 784 (2003)

17.I.A. Petrov, Evaluation of the effectiveness of vibration protection systems with nonlinear characteristics (dissertation for the candidate of technical sciences) 119 (2013)

18. E. Elvira, P. Mendis, A. Whittaker, Civil Engineering Dimension, Numerical Simulation of threat-independent progressive collapse, 13, 29 (2011)

19. T. Zoli, R. Woodward, International journal of impact engineering, Design of long span bridges for cable loss, 32(1), 39 (2007)

20. GOST 380-2005 Common quality carbon steel. Grades 7 (2008) 